\title{
Flexural and Tensile Characteristics of Micro Fiber-Reinforced Very High Strength Concrete Thin Panels
}

\author{
Taher M. Abu-Lebdeh, Ellie Fini and Monique Lumpkin \\ Department of Civil, Architectural and Environmental Engineering, \\ North Carolina A and T State University, NC 27411, Greensboro
}

Received 2012-08-01, Revised 2012-08-07; Accepted 2012-08-15

\begin{abstract}
The purpose of this research was to experimentally characterize the flexural and tensile characteristics of fiber-reinforced Very High-Strength Concrete (VHSC) panels. The panels were made with a unique mix of cementitous materials achieving compressive strength of 26,000 psi (180 MPa) or greater. VHSC panels were reinforced with polypropylene fibers of 1 inch $(25.4 \mathrm{~mm})$ in length and Polyvinyl alcohol (PVA) micro-fibers of $1 / 2$ inch length, incorporated at $1.5 \%$ by volume. For the flexural behavior, $17 \times 2 \times 3 / 4$ inch flat panels were tested under third-point loading tests, while the direct tension experiments were tested on $10 \times 3 \times 1 / 2$ inch tension panels under a direct tensile load. Flexural tests were conducted on three panels of plain VHSC, three panels of VHSC reinforced with polypropylene fibers and three panels of VHSC reinforced with $1 / 2$ inch micro-fibers. Similar testing program was used to conduct the direct tension tests. Also, compression test conducted on $2 \times 2 \times 2$ inch cubes and compressive test conducted on 4 inch by 8 inch cylinders test were used to establish compressive strength and modulus of elasticity respectively. Results show that the compressive strength, tensile strength and fracture toughness of the VHSC panels were much greater than those normally obtained by typical concrete material. The presence of fibers increases the toughness of VHSC specimens between 80 and $190 \%$ and increases the tensile strength by 23 to $47 \%$. The modulus of elasticity and Poisson's ratio recorded herein were determined according to ASTM C 469-02. Laboratory experiments on flexural and tensile properties of thin, very high-strength, fiber reinforced concrete panels, were used to study the material and characterize the panels' reaction to load. Parameters such as compressive strength, tensile strength, toughness, elastic modulus, Poisson's ratio and first-crack strength were determined and may be considered for potential use as design parameters in future material improvements.
\end{abstract}

Keywords: Very High Strength Concrete, Micro Fiber, Tensile Strength, Flexural Strength, Toughness, Elastic Modulus, First-crack Strength, Fracture Energy

\section{INTRODUCTION}

Over the past decade engineering applications have maintained a direct focus, as part of the continued development of new and innovative construction materials, on high performance concrete. Very High Strength Concrete (VHSC) with improved properties of strength and toughness is relatively new category of concrete classifications developed by the U.S. Army Engineer Research and Development Center (ERDC). Having the same general components of the conventional concrete, the tensile and compressive strength, toughness and durability are all improved properties for this new material. Test results on very high strength concrete revealed that compressive and tensile strengths could reach 29,000 psi (200MPa) or greater and $1,450 \mathrm{psi}$ $(10 \mathrm{MPa})$ or greater, respectively. These superior properties were achieved by considering several factors such as low flaws, particle packing, improved material homogeneity, low water cement ratio, mixing method and special curing treatment (Abu-Lebdeh et al., 2010; O'Neil et al., 1999; 2006; Rossana, 2012). The particle 
packing theory is used to aid the materials homogeneity and therefore reducing flaws. Limiting the number and size of voids by selecting materials that are close in volume involves a procedure called particle packing. The smallest particles in VHSC fill the voids between the larger particles therefore reducing the number of potential flaws in the matrix. VHSC's sand is the largest particle size, the next largest is cement. The smallest particle size in VHSC is silica fume. The element volumes of these particles are chosen to attain the greatest density of the paste. The greater the density makes the constituent have fewer and smaller voids, thus the higher the strength of the paste. The most significant hydration product in cement paste is Calcium Silicate Hydrate (CSH), which can be increased by the presence of high silica content. The maximization of silica content in VHSC minimizes differential strain under stress from components with different moduli of elasticity and also maximizes CSH. Additional strength of VHSC is achieved by using a water-to-cement ratio of 0.25 , which is possible because of the use of a High-Range Water Reducing Admixture (HRWRA). VHSC keeps the volume of water low at a water to cement ratio of 0.25 to insure there is no excess of water. The volume of water is only needed to hydrate the cement in the hydration reaction process. To insure the fluidity of otherwise very stiff concrete, HighRange-Water-Reducing Admixtures (HRWRA) is used with water to increase workability of the concrete. Cement grains repel each other through the HRWRA negatively charged cement grains, which allows water to contact the grains entire surface area. The additional benefits of HRWRA were studied by The U.S. Army Corps Engineers, where a series of VHSC mixtures were made changing only the HRWRA content and brand of HRWRA. The results revealed that strength was not a function of HRWRA dosage; however the brand of HRWRA did affect strength. Curing VHSC at elevated temperatures of $90^{\circ} \mathrm{C}$ causes a chemical phase change to occur, resulting in additional strength. The seven day strengths ranged from $18,000 \mathrm{psi}(124 \mathrm{MPa})$ to $20,000 \mathrm{psi}$ $(138 \mathrm{MPa})$ while the twenty eight day strengths ranged from 19,000 psi (131 MPa) to 26,000 psi (179 MPa).

Very high strength concrete exhibits near-linear stress-strain characteristics up to failure, thus extremely brittle. O'Neil et al. (1999) co-investigators describe the tensile properties of VHSC with and without fibers. When the compressive strength is on the order of $180 \mathrm{MPa}(26,000 \mathrm{psi})$ the direct tensile strength of VHSC may only be $10 \mathrm{MPa}(1,450 \mathrm{psi})$. With the addition of fibers the first-crack loads, ultimate load-bearing capacity and flexural toughness all increase (Nelson et al., 2002; Li and Wang, 2006; Kanda and Li, 1999). Without the addition of fibers the stress-strain characteristics are nearly linearly elastic and brittle. This brittle behavior may be characterized with the complete loss of tensile stress upon first cracking (O’Neil et al., 1999). Significant studies have been conducted to improve the tensile characteristics of such cementitous materials. Several of these investigations focused on the inclusion and effect of discontinuous reinforcement, emphasizing the influence of short, randomly distributed fibers on concrete's tensile characteristics (Banthia and Gupta, 2004; Ravichandran et al., 2009; Ramli, 2010; Chandramouli et al., 2010). The experimental and analytical results revealed that the addition of discontinuous fibers to the cementitious matrix can have a significant influence on post-crack ductility and greatly improves toughness. The fibers cross the paths of potential cracks and transmit stress between the fibers and the matrix through the interfacial bond. A good interfacial bond provides high resistance to fiber pullout, thus greatly increases the material's toughness. The effectiveness of a given fiber as a medium of stress transfer is a function of several components such as chemical adhesion between the fiber and matrix, fiber length, orientation and the mechanical component such as hooked, flattened end or smooth. The author and coinvestigators (Abu-Lebdeh et al., 2010) performed a comprehensive experimental program on fiber pullout tests using VHSC as the medium from which the fibers were pulled. Several different parameters were investigated in the experimental program including embedment length, concrete strength, fiber types (smooth, hooked, flat end and helical), pullout rate and the embedment method. The main objective was to experimentally investigate different bond mechanisms in the VHSC and generate data to aid in the development of analytical models that describe bond in fiber reinforced cement-based composites. The results of the investigation are important to better understand the effects that fiber geometry, matrix properties and loading have on bond-slip characteristics.

The main objective of this investigation is to better understand the interaction between fibers and the VHSC cementitous matrix by conducting an experimental investigation to study the effect of adding fiber and microfibers and to improve ductility and toughness of VHSC. To obtain the experimental means for the given objective, multiple experiments were used to characterize the response of thin fiber reinforced VHSC panels to flexural and tensile loads. Flexural third-point bending experiments were used to characterize the panels' pre-and post-crack response in flexure and direct tension experiments were used to confirm the findings from the flexural experiments and to directly measure the VHSC material's tensile strength and ductility. 


\section{MATERIALS AND METHODS}

\subsection{Specimen Preparation}

The experimental program was designed to investigate the effect of fibers on the flexural and tensile behavior of Very High Strength Concrete (VHSC) material and to characterize the response of thin very high-strength FRC panels to flexural and tensile loads. Three different types of specimens, namely: (1) plain VHSC; (2) VHSC reinforced with PVA micro-fiber; and (3) VHSC reinforced with polypropylene fibers were prepared and tested for compression, flexural and direct tension. Each type consists of nine $2 \times 2 \times 2$ inch Cubes and three $4 \times 8$ inch cylinders for compression test, three panels for flexural and three specimens for tension. Two different types of fibers were used: Polyvinyl Alcohol (PVA) micro-fibers (Nycon Reinforcing Fibers Corporation, Nycon RFS400) with lengths $1 / 2$ inch (13 $\mathrm{mm}$ ) and Alkali-Resistant (AR) polypropylene fiberglass fibers (Nippon Electric Glass Corporation, AR2500 H103 fiber) chopped to 1 inch $(25 \mathrm{~mm})$ length. The fibers were mixed with the VHSC components at approximately $1.5 \%$ Table 1 .

The VHSC mix consisted of sand, cement, silica flour, silica fume, HRWRA and water. Proportions and mixing procedures are described by the authors elsewhere (Abu-Lebdeh et al., 2010). Several batches were prepared for the test program, each batch consisted of one flexural specimen, one tension specimen, one 4 by 8 in cylinder and three $2 \times 2 \times 2$ inch cubes. Cubes were prepared in solid brass molds. After casting and vibrating, specimens were placed in plastic bags with wet burlap for up to 48 hours; the specimens were then removed from the molds and placed in a lime saturated water curing tank for seven days at room temperature. Subsequent to the seven days in the tank, the VHSC specimens were placed in a water pail placed in an oven set at $90^{\circ} \mathrm{C}$ for four days. Following the four days in the pail the specimens were removed from the pail and returned to the oven at $90^{\circ} \mathrm{C}$ for an additional two days. Then, all specimens were soaked in the water tank for a period of not less than 24 hours and not more than 72 hours prior to testing. The dimensions of the flexural panel specimen were $17 \times 2 \times 3 / 4$ inch and cast from an $18 \times 7 \frac{1}{2}$ inch steel mold as shown in Fig. 1. These measurements were decided based on the machine capacity and clear span length according to ASTM C947-03 testing method. Specimen for the direct tension test was designed similar to a typical dog-bone shape used in steel coupon tensile test. The dimensions of the tension specimen were $10 \times 3 \times 1 / 2$ inch with a cross bone section $1 \times 2$ inch and cast from a $12 \times 4$ inch Figure 2 .
The cross bone shape in the tension specimens was designed to control the location of crack formation.

\subsection{Test Setup and Testing Procedures 2.2.1. Flexural Testing}

Instron 5500R testing machine was used to carry out the flexural third-point loading tests. Testing was conducted in accordance with ASTM (2009) standards in a closed-loop manner, which provided displacement rate control. The displacement rate was set to $0.05 \mathrm{inch} \mathrm{min}^{-1}$ $\left(1.27 \mathrm{~mm} \mathrm{~min}{ }^{-1}\right)$. Loading nose of the testing machine (Fig. 3) has cylindrical surfaces in order to avoid excessive indentation or failure due to stress concentration directly under the loading noses or supports. The loading head allowed rotation to occur about the axes that lie in horizontal planes of the loading apparatus. This configuration was used to ensure that forces applied to the specimen were perpendicular to the surfaces of the specimen and applied without eccentricity. The major span (distance between the supports) of the test apparatus was set at 12 inches in accordance of having a ratio of the specimen major span length to the specimen depth of 16 to 1 . The minor span (One third of the major span) was set at 4 inches. The specimen was centered on the supports with equal lengths of $2 \frac{1}{2}$ inch $(63.5 \mathrm{~mm})$ projecting outside the supports with the long axis of the specimen set perpendicular to the loading noses and supports (Fig. 3).

\subsection{Direct Tension Tests}

Unlike flexural test, direct tension experimentation doesn't have a standardized procedure available. Due to the lack of standard test methods, the U.S Army "ERDC" testing procedures (Roth, 2008) was adopted herein to conduct the direct tension tests. A rigid connection plate [3 inch $(76.2 \mathrm{~mm})$ wide, 3 inch $(76.2 \mathrm{~mm})$ long and 0.5 inch $(12.7 \mathrm{~mm})$ thick with $2 \times 1 / 2$ inch rectangles cut from each side], shown in Fig. 4 was designed and locally manufactured to be attached to the specimen with Sika Dur 31 Hi-Mod epoxy. This rigid connection is utilized to minimize the potential for a non-uniform crack opening at the cracked area and to prevent crushing of the specimens from the loading fixtures. The Forney testing machine with a capacity of 400 kips was utilized for this test. The loading fixture was changed to grips to properly pull specimen in opposite directions. After completion of replacing the loading fixture the test specimens were connected to the loading fixture and leveled vertically and horizontally before direct tension load could be applied, as shown in Fig. 5. The loading rate was constant at a rate of $12,000 \mathrm{lbs}^{\mathrm{bin}}{ }^{-1}$ until failure. The maximum load allowed by the specimen was recorded and the ultimate tensile strength was found. 
Taher M. Abu-Lebdeh et al. / American Journal of Engineering and Applied Sciences 5 (2) (2012) 184-197

Table 1: Fibers' properties

\begin{tabular}{lllll}
\hline Fiber & Material & $\begin{array}{l}\text { Length } \\
\text { inch }(\mathrm{mm})\end{array}$ & $\begin{array}{l}\text { Density } \\
\mathrm{lb} / \mathrm{ft}^{3}\left(\mathrm{~g} / \mathrm{cm}^{3}\right)\end{array}$ & $\begin{array}{l}\text { Tensile Strength } \\
\mathrm{ksi}(\mathrm{MPa})\end{array}$ \\
\hline Micro-Fiber & PVA & $1 / 2(12.5)$ & $81.16(1.3)$ & $160-203(1100-1400)$ \\
Polypropylene & AR & $1(24.4)$ & $168(2.7)$ & $184-355(1270-2450)$ \\
\hline
\end{tabular}
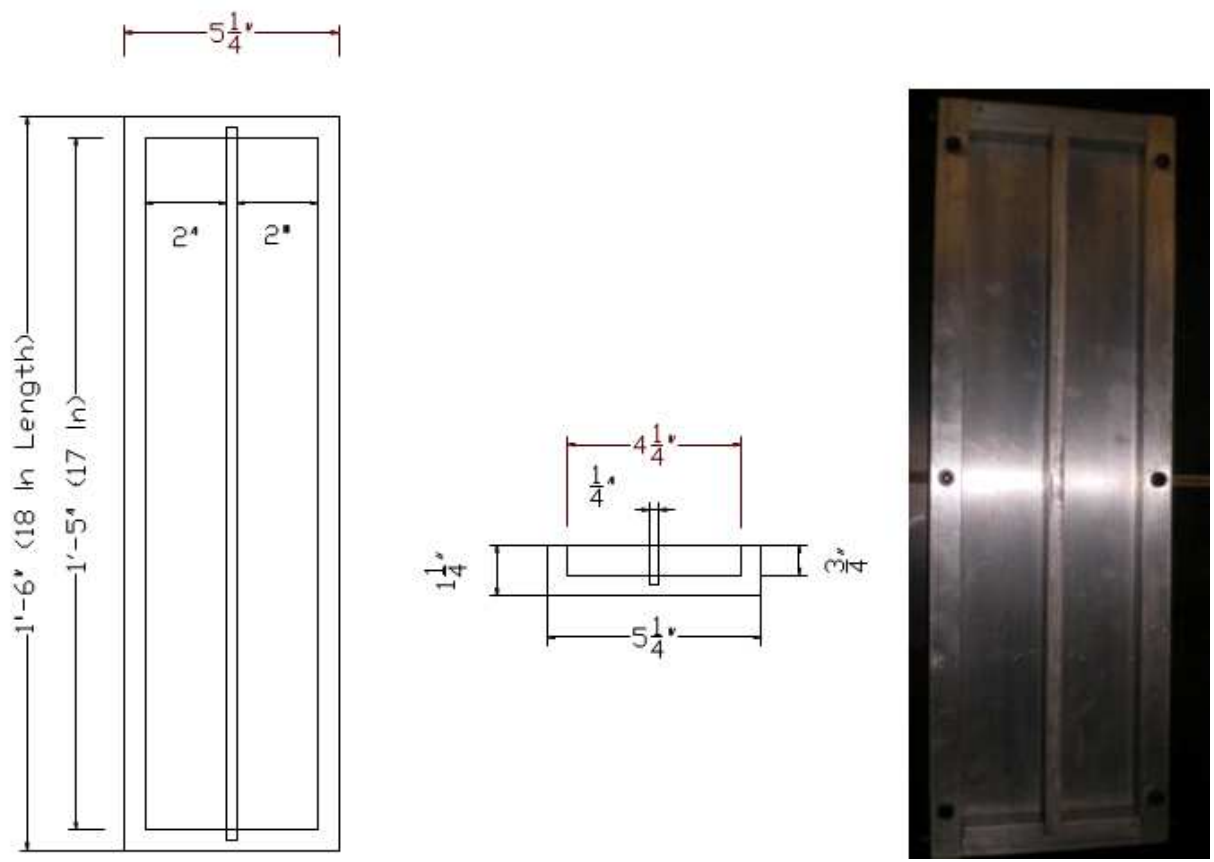

Fig. 1. Flexural panel mold
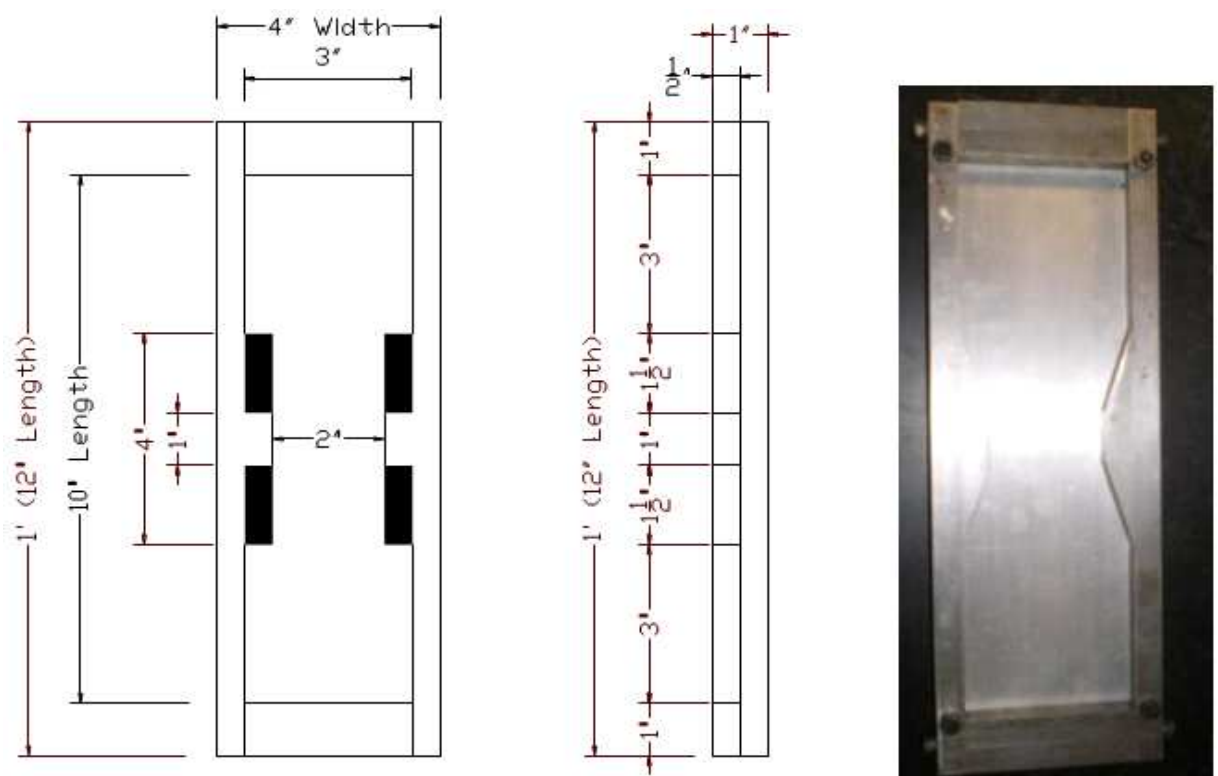

Fig. 2. Tension specimen mold 
Taher M. Abu-Lebdeh et al. / American Journal of Engineering and Applied Sciences 5 (2) (2012) 184-197

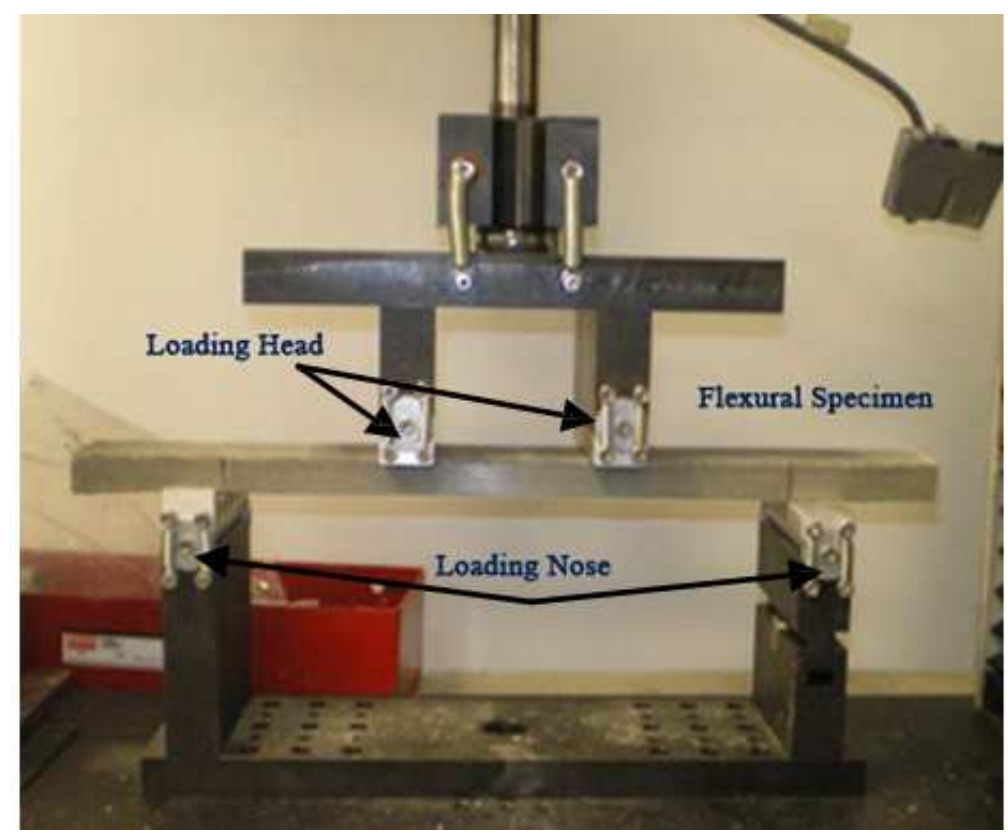

(a)

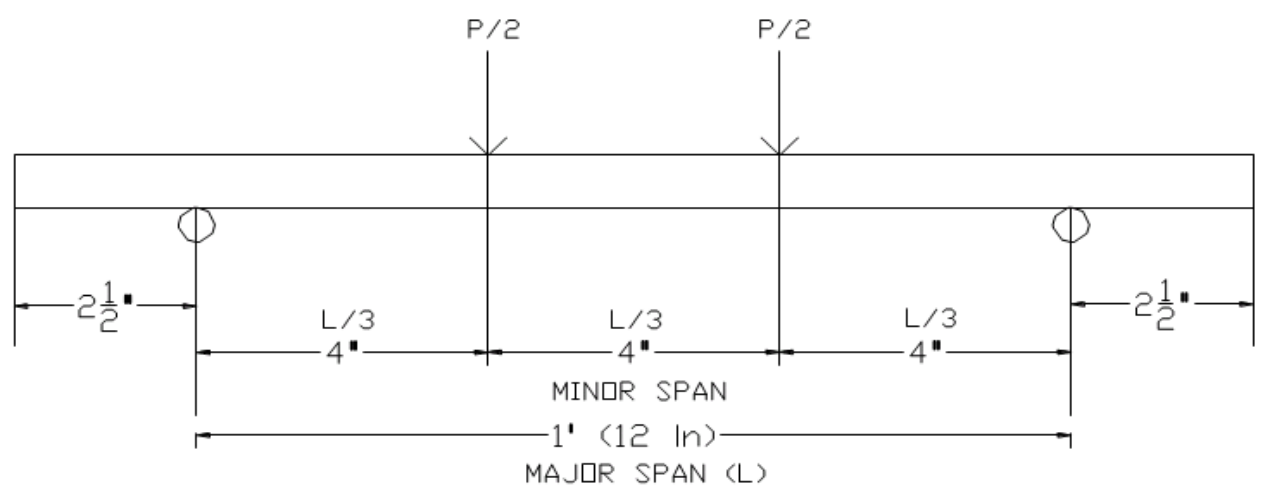

(b)

Fig. 3. Flexural test set-up (a) Test setup (b) Span Length
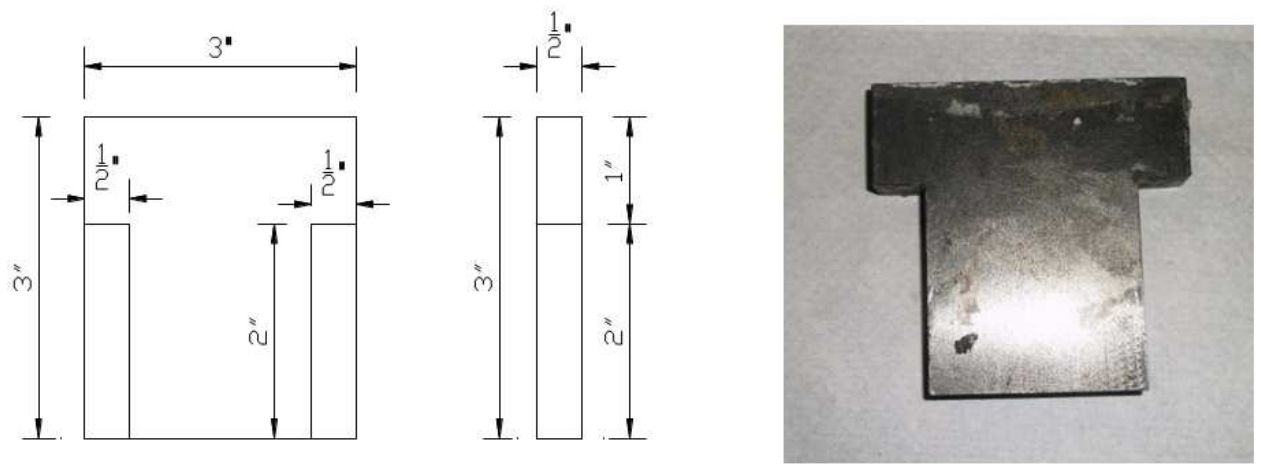

Fig. 4. Rigid Plate Dimensions 


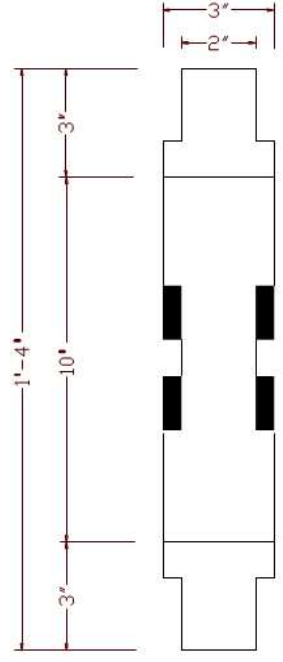

(a)

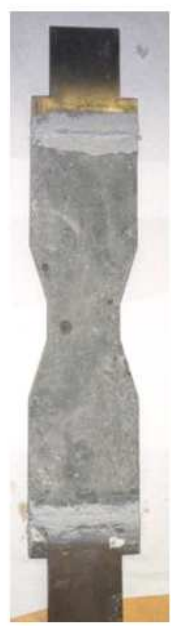

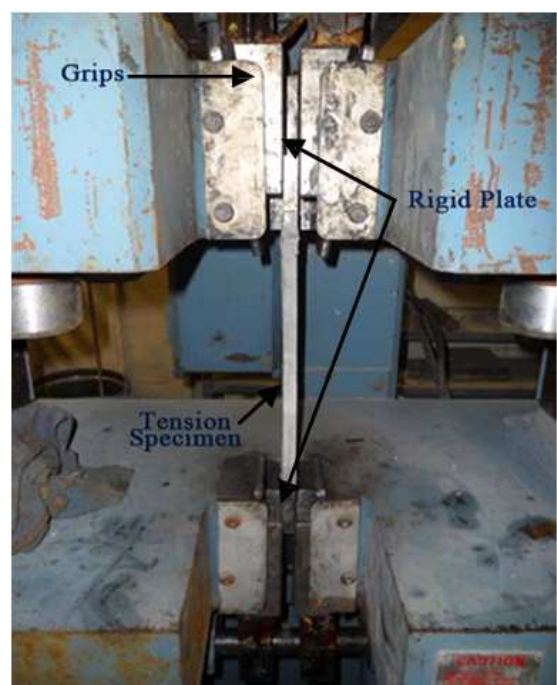

(b)

Fig. 5. Direct tension test set-up (a) tension specimen (b) tension loading fixture and rigid plate attachment

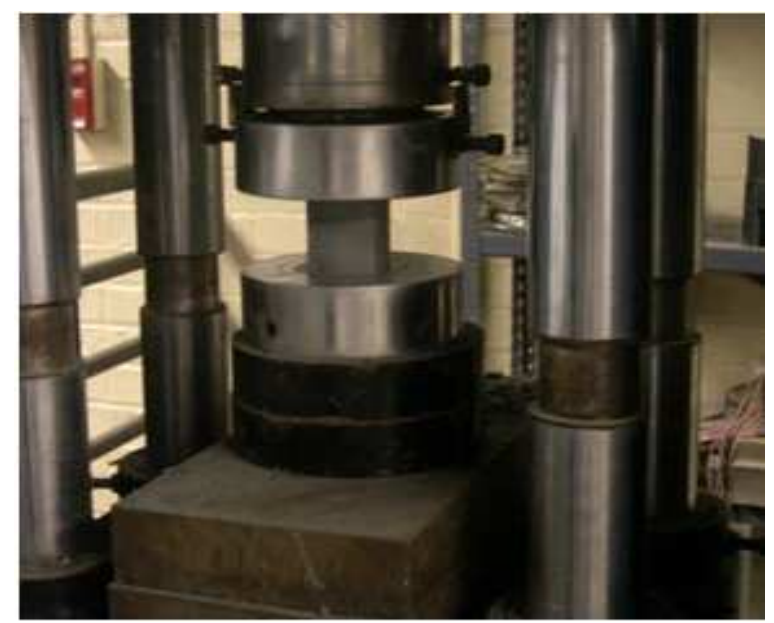

Fig. 6. Compression test set-up

It should be noted that, for meaningful direct tension data, one should certain the application of axial tensile loading without eccentricity to the specimen. This would cause pure tensile loading condition to be achieved; and provide sufficient rigidity in the testing apparatus so that the crack opens uniformly across the width of the specimen.

\subsection{Compression Tests}

As previously stated, $4 \times 8$ in cylinder and 2 inch cubes of VHSC specimens were prepared from each batch of VHSC flexural and tension specimens, so that the compressive strength of the batch could be determined.

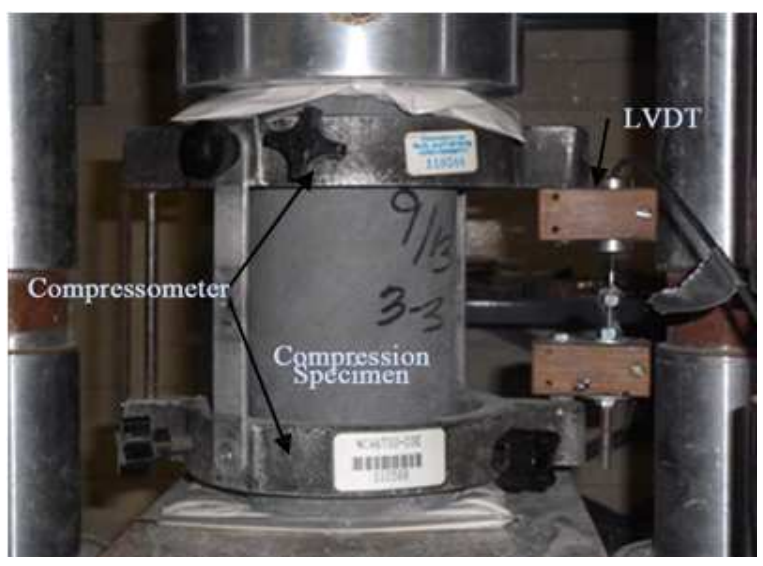

Fig. 7. Determination of modulus of elasticity

The Forney testing machine (Fig. 6) was used for the compression test. The loading rate was $12,000 \mathrm{lbs} \mathrm{min}^{-1}$. The maximum loads were recorded and the compressive strength of each batch of VHSC specimens was determined. The 4 inch by 8 inch cylinders were tested, using the same loading set-up, to determine the modulus of elasticity of very high strength concrete under longitudinal compressive stress in accordance with ASTM(2002). A Linear Variable Differential Transformer (LVDT) was used to measure the longitudinal strain. A compressometer consisting of two yokes is used in coordination with a LVDT to measure deformation as shown in Fig. 7. The load was applied at a rate of 0.05 in $\min ^{-1}$ and the readings of compression stress and longitudinal strain was recorded at strain of 50 micron 
and at $40 \%$ of the ultimate load. The modulus of Elasticity (E) was calculated according to ASTM (2002) using equation 1 :

$$
\mathrm{E}=\left(\mathrm{S}_{2}-\mathrm{S}_{1}\right) /\left(\epsilon_{2}-0.000050\right)
$$

where, $\mathrm{S}_{2}$ is the stress corresponding to $40 \%$ of the ultimate load, $S_{1}$ is the stress corresponding to a longitudinal strain of 50 micron and $\epsilon_{2}$ is the longitudinal strain produced by stress $\mathrm{S}_{2}$.

\section{RESULTS}

\subsection{Compressive Strength}

Results of the compression test are tabulated in Table 2. Results include the average unconfined compressive strength and standard deviation, measured from testing of 2 inch cubes specimens made from plain VHSC, VHSC with micro-fiber and VHSC with polypropylene. The average unconfined compressive strength for plain VHSC specimens is 23,486 psi (162 MPa), VHSC specimens with micro-fiber produced 20,122 psi (139 MPa) and VHSC specimens with polypropylene fibers produced 16,569 psi $(114 \mathrm{MPa})$, where all are higher than 6000 psi (41.4 MPa) therefore they are considered high strength.

\subsection{Flexural Properties}

Nine specimens were tested for flexural using thirdpoint test in accordance with ASTM (2009). Three thin panels were made from plain VHSC, three panels of VHSC with micro-fibers and three panels made of VHSC with polypropylene fibers. Load-displacement histories were plotted for each flexural test. The load where the load-deflection curve deviates from linearity $\left(\mathrm{P}_{\mathrm{y}}\right)$ and its corresponding deflection $\left(\delta_{\mathrm{y}}\right)$ were recorded. Further, the maximum load attained $\left(\mathrm{P}_{\mathrm{u}}\right)$ and its corresponding displacement $\left(\delta_{\mathrm{u}}\right)$ were also recorded. Nine load-displacement histories for flexural test results are shown individually in Fig. 8-10.

Table 2. Compression Test Results

\begin{tabular}{|c|c|c|c|c|c|}
\hline \multicolumn{2}{|l|}{ Plain VHSC } & \multicolumn{2}{|c|}{ VHSC/microfiber } & \multicolumn{2}{|l|}{ VHSC/fiber } \\
\hline Peak Load & Strength & Peak Load & Strength & Peak Load & Strength \\
\hline (lb) & (psi) & (lb) & (psi) & (lb) & (psi) \\
\hline 92,460 & 23,115 & 75,780 & 18,945 & 62,707 & 15,677 \\
\hline 101,920 & 25,480 & 88,712 & 22,178 & 70,163 & 17,541 \\
\hline 89,735 & 22,434 & 84,710 & 21178 & 63,479 & 15,870 \\
\hline 93,201 & 23,300 & 83,459 & 20,865 & 67,480 & 16,870 \\
\hline 86,082 & 21,521 & 72,555 & 18,139 & 71,338 & 17,835 \\
\hline 106,800 & 26,700 & 82,520 & 20,630 & 61,877 & 15,469 \\
\hline 102,450 & 25,613 & 78,345 & 19,586 & 61,541 & 15,385 \\
\hline 77,776 & 19,444 & 77,813 & 19,453 & 69,785 & 17,446 \\
\hline 95,080 & 23,770 & & & 68,112 & 17,028 \\
\hline Average & 23,486 & & 20,122 & & 16,569 \\
\hline Std. Div. & 2,247 & & 1,320 & & 969 \\
\hline
\end{tabular}

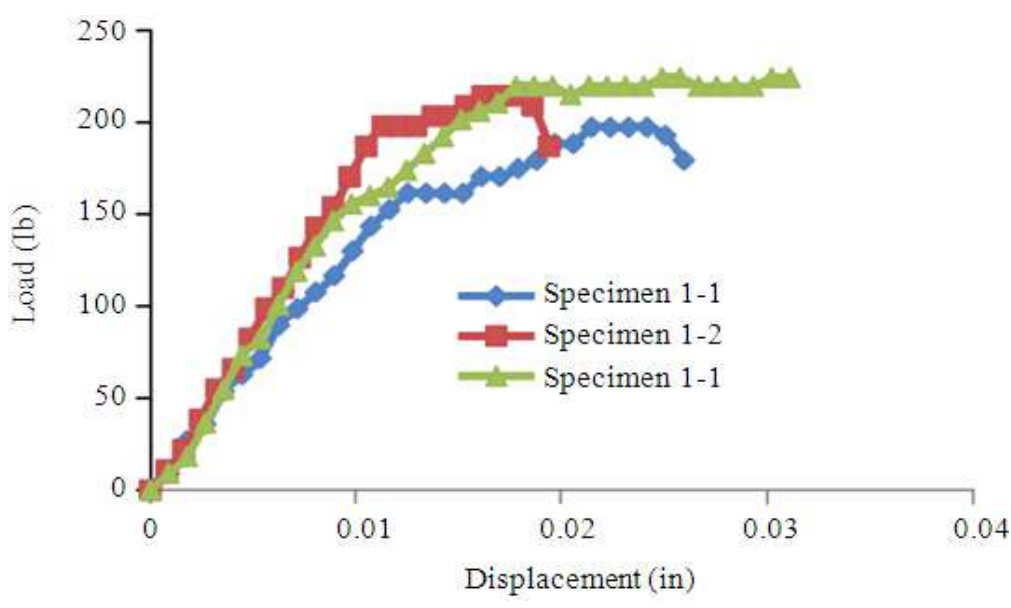

Fig. 8. Flexural load Vs. displacement histories: Plain VHSC 
Taher M. Abu-Lebdeh et al. / American Journal of Engineering and Applied Sciences 5 (2) (2012) 184-197

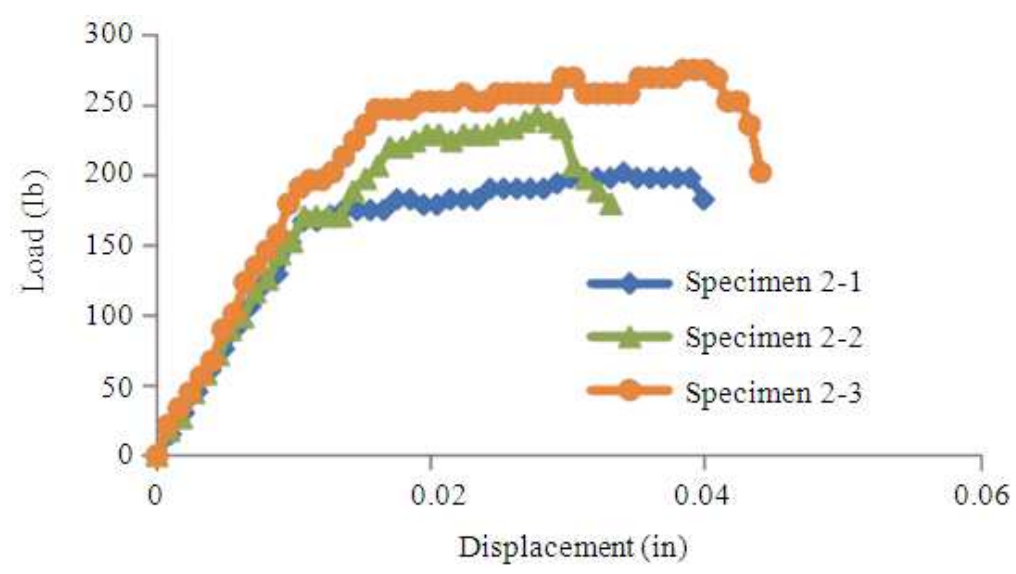

Fig. 9. Flexural load Vs. displacement histories: VHSC with micro-fiber

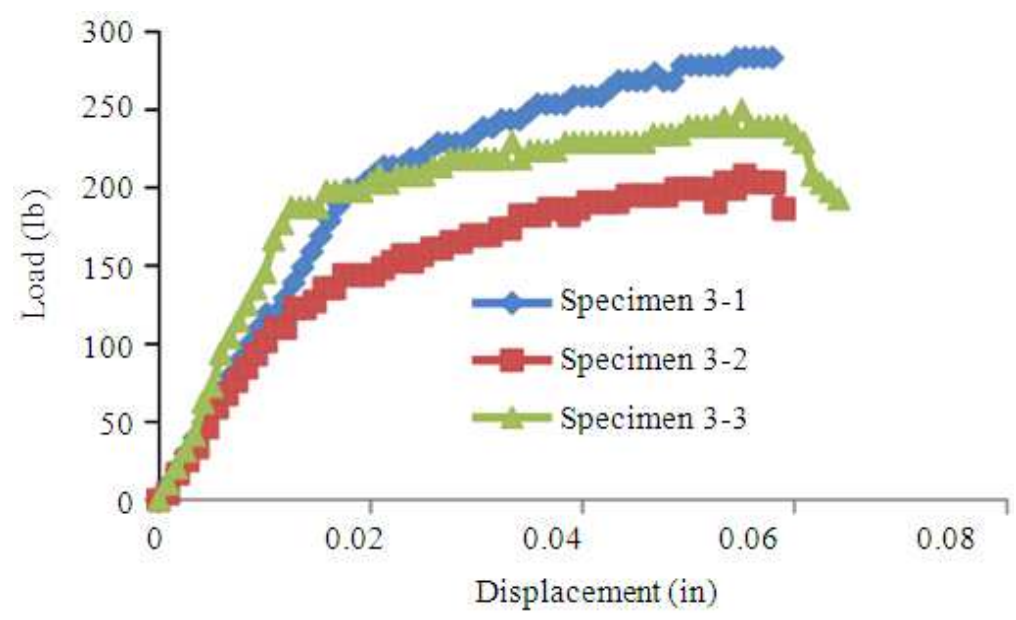

Fig. 10. Flexural Load vs. Displacement Hisotries: VHSC with Polypropylene

Table 3. Summary of Flexural VHSC Panels' Mechanical Properties

\begin{tabular}{|c|c|c|c|c|c|c|c|c|}
\hline Specimen & & $\begin{array}{l}\mathrm{P}_{\mathrm{y}} \\
\mathrm{Lb}\end{array}$ & $\begin{array}{l}\mathrm{P}_{\mathrm{u}} \\
\mathrm{Lb}\end{array}$ & $\begin{array}{l}\delta_{\mathrm{y}} \\
\text { in } \\
\end{array}$ & $\begin{array}{l}\delta_{\mathrm{u}} \\
\text { in } \\
\end{array}$ & $\begin{array}{l}\sigma_{\mathrm{y}} \\
\text { psi }\end{array}$ & $\begin{array}{l}\mathrm{E}_{\text {initial }} \\
\mathrm{psi}\end{array}$ & $\begin{array}{l}\mathrm{E}_{\text {reduced }} \\
\text { psi }\end{array}$ \\
\hline \multirow[t]{3}{*}{ Plain VHSC } & $1--1$ & 159.30 & 200.90 & 0.0126 & 0.0236 & 1699.0 & $4.804 \mathrm{E}+06$ & $1.421 \mathrm{E}+06$ \\
\hline & $1--2$ & 198.80 & 219.90 & 0.0111 & 0.0175 & 2121.0 & $6.795 \mathrm{E}+06$ & $1.250 \mathrm{E}+06$ \\
\hline & $1--3$ & 150.90 & 231.40 & 0.0093 & 0.0311 & 1609.0 & $6.143 \mathrm{E}+06$ & $1.402 \mathrm{E}+06$ \\
\hline Mean & & 169.60 & 217.40 & 0.0110 & 0.0241 & 1810.0 & $5.91 \mathrm{E}+06$ & $1.36 \mathrm{E}+06$ \\
\hline Standard Deviation & & 25.59 & 15.44 & 0.0016 & 0.0069 & 273.0 & $1.02 \mathrm{E}+06$ & $9.37 \mathrm{E}+04$ \\
\hline VHSC w/ Micro- & $2--1$ & 164.70 & 203.70 & 0.0106 & 0.0390 & 1757.0 & $5.893 \mathrm{E}+06$ & $5.208 \mathrm{E}+05$ \\
\hline \multirow[t]{2}{*}{ fibers } & $2--2$ & 170.00 & 243.50 & 0.0110 & 0.0277 & 1813.0 & $5.877 \mathrm{E}+06$ & $1.659 \mathrm{E}+06$ \\
\hline & $2--3$ & 199.70 & 273.90 & 0.0111 & 0.0398 & 2130.0 & $6.842 \mathrm{E}+06$ & $9.805 \mathrm{E}+05$ \\
\hline Mean & & 178.10 & 240.40 & 0.0109 & 0.0355 & 1900.0 & $6.20 \mathrm{E}+06$ & $1.05 \mathrm{E}+06$ \\
\hline Standard Deviation & & 18.87 & 35.21 & 0.0002 & 0.0067 & 201.3 & $5.52 \mathrm{E}+05$ & $5.73 \mathrm{E}+05$ \\
\hline VHSC w/ Polyp. & $3--1$ & 204.20 & 283.90 & 0.0187 & 0.0557 & 2178.0 & $4.147 \mathrm{E}+06$ & $8.147 \mathrm{E}+05$ \\
\hline \multirow[t]{2}{*}{ fibers } & $3--2$ & 152.40 & 223.20 & 0.0128 & 0.0567 & 1626.0 & $4.503 \mathrm{E}+06$ & $6.117 \mathrm{E}+05$ \\
\hline & $3--3$ & 183.30 & 256.70 & 0.0121 & 0.0556 & 1956.0 & $5.731 \mathrm{E}+06$ & $6.391 \mathrm{E}+05$ \\
\hline Mean & & 180.00 & 254.60 & 0.0145 & 0.0560 & 1920.0 & $4.79 \mathrm{E}+06$ & $6.88 \mathrm{E}+05$ \\
\hline Standard Deviation & & 26.03 & 30.42 & 0.0036 & 0.0006 & 277.7 & $8.31 \mathrm{E}+05$ & $1.10 \mathrm{E}+05$ \\
\hline
\end{tabular}


For each of the records shown, flexural panel properties are given in Table 3, which include: Load at first-crack formation $\left(\mathrm{P}_{\mathrm{y}}\right)$; Ultimate load $\left(\mathrm{P}_{\mathrm{u}}\right)$; Displacement at first crack $\left(\delta_{\mathrm{y}}\right)$; Displacement at ultimate load $\left(\delta_{\mathrm{u}}\right)$; Firstcrack strength $\left(\sigma_{\mathrm{y}}\right)$; Initial flexural elastic modulus $\left(\mathrm{E}_{\text {initial }}\right)$; and Post-crack flexural modulus $\left(\mathrm{E}_{\text {reduced }}\right)$. The first-crack strength $\left(\sigma_{y}\right)$ and the initial flexural elastic modulus $\left(\mathrm{E}_{\text {initial }}\right)$ shown in Table 3 , were computed using ASTM C947-03 as follows equation 2 and 3:

$$
\begin{aligned}
& \sigma_{y}=P_{y} L / b d^{2} \\
& E=\frac{5 P_{y} L^{3}}{27 \delta_{y} b d^{3}}
\end{aligned}
$$

Where:

$\sigma_{\mathrm{y}}=$ First-crack strength, psi or MPa

$\mathrm{P}_{\mathrm{y}}=$ Load (measured from the load cell)

where, the load-deflection curve deviates from linearity:

$\mathrm{lb}$ or $\mathrm{N}=$ Span between centerline of supports, inch or $\mathrm{mm}$

$\mathrm{b} \quad=$ Panel width, inch or $\mathrm{mm}$

$\mathrm{d}=$ Mean panel thickness, inch or $\mathrm{mm}$

$\delta_{\mathrm{y}} \quad=$ Displacement corresponding to $\mathrm{P}_{\mathrm{y}}$

The reduced flexural modulus $\left(\mathrm{E}_{\text {reduced }}\right)$ tabulated in Table 3 and shown in Equation 4 can be calculated in the same manner as the initial flexural modulus, (Equation 3) where $\mathrm{P}_{\mathrm{u}}$ and $\delta_{\mathrm{u}}$ are the ultimate load and its corresponding displacement respectively:

$$
\mathrm{E}_{\text {reduced }}=\frac{5\left(\mathrm{P}_{\mathrm{y}}-\mathrm{P}_{\mathrm{u}}\right) \mathrm{L}^{3}}{27\left(\delta_{\mathrm{y}}-\delta_{\mathrm{u}}\right) b \mathrm{~d}^{3}}
$$

To provide for direct comparison between the specimen responses, all of the load-displacement histories are plotted in Fig. 11. The specimens exhibited reasonable uniformity in their initial linear response and point of first-crack formation. From the graphs it is also seen that the greatest variability in the specimen response was the ultimate displacement; with magnitude ranging from approximately 0.0175 inch $(0.44 \mathrm{~mm})$ to 0.0311 inch $(0.79 \mathrm{~mm})$, or equivalent to 2 to $4 \%$ of the specimen thickness for plain VHSC, from 0.0277 inch $(0.70 \mathrm{~mm})$ to 0.0398 inch $(1.01 \mathrm{~mm})$ equivalent to 4 to $5 \%$ for VHSC with micro-fibers and from 0.0556 inch (1.41 $\mathrm{mm})$ to 0.0567 inch $(1.44 \mathrm{~mm})$ equivalent to 7 to $8 \%$ for VHSC with polypropylene fibers.

Toughness or fracture energy of a specimen (area under the load-deflection curve) was calculated for all specimens subjected to third-point bending tests. Results of the plain VHSC specimens, VHSC specimens with micro-fiber and VHSC with polypropylene fiber are summarized in Table 4. As seen, the fracture energy increases with the presence of fibers and with the increase in fiber length. The increase in fracture energy was $90 \%$ and $187 \%$ due to the addition of the $1 / 2$ inch PVA micro-fibers and 1 inch long polypropylene fiber, respectively.

\subsection{Direct Tension Results}

Nine tests were conducted as part of the direct tension experiments. In Tests 1-1 and 2-2, the specimens failed prematurely at the rigid cap connection due to the epoxy failure.

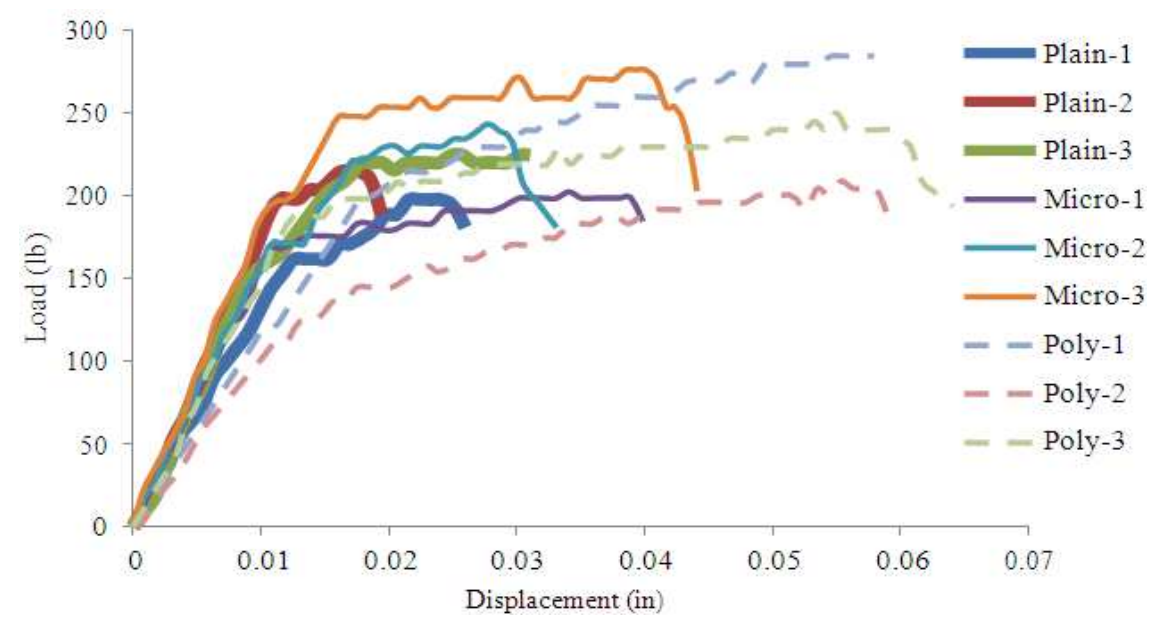

Fig. 11. Flexural load Vs. displacement histories: all flexural specimens 
Table 4. Fracture Energy of VHSC panels

\begin{tabular}{|c|c|c|c|}
\hline Specimen & & $\begin{array}{l}\text { Area Under } \\
\text { The Curve } \\
\text { (lbf-in) }\end{array}$ & $\begin{array}{l}\text { Fracture Energy } \\
\left(\mathrm{lbf}-\mathrm{in} / \mathrm{in}^{2}\right)\end{array}$ \\
\hline \multirow[t]{5}{*}{ Plain VHSC } & $1--1$ & 3.28 & 2.19 \\
\hline & $1--2$ & 2.92 & 1.95 \\
\hline & $1--3$ & 4.96 & 3.30 \\
\hline & Mean & 3.72 & 2.48 \\
\hline & Stdev & 1.09 & 0.72 \\
\hline \multirow{5}{*}{$\begin{array}{l}\text { VHSC w/ Micro- } \\
\text { fibers }\end{array}$} & $2--1$ & 6.13 & 4.09 \\
\hline & $2--2$ & 6.05 & 4.04 \\
\hline & $2--3$ & 8.97 & 5.98 \\
\hline & Mean & 7.05 & 4.70 \\
\hline & Stdev & 1.66 & 1.11 \\
\hline VHSC w/ Polypropy & $3--1$ & 12.37 & 8.25 \\
\hline \multirow[t]{4}{*}{-lene fibers } & $3--2$ & 7.73 & 5.15 \\
\hline & $3--3$ & 11.88 & 7.92 \\
\hline & Mean & 10.66 & 7.11 \\
\hline & Stdev & 2.55 & 1.70 \\
\hline
\end{tabular}

Table 5. Tensile strength of fiber reinforced VHSC specimens

\begin{tabular}{llll}
\hline Specimen & & $\begin{array}{l}\text { Max Load } \\
(\mathrm{lb})\end{array}$ & $\begin{array}{l}\text { Strength } \\
(\mathrm{psi})\end{array}$ \\
\hline Plain VHSC & $1--1$ & --- & ---- \\
& $1--2$ & 885 & 885 \\
& $1--3$ & 920 & 920 \\
& Mean & 903 & 903 \\
VHSC w/ Micro-fibers & Stdev & 24.75 & 24.75 \\
& $2--1$ & 1130 & 1130 \\
& $2--2$ & ---- & --- \\
& $2--3$ & 1090 & 1090 \\
VHSC w/ Polypropylene & Mean & 1110 & 1110 \\
fibers & Stdev & 28.28 & 28.28 \\
& $3--1$ & 1292 & 1292 \\
& $3--3$ & 1356 & 1356 \\
& Mean & 1334 & 1334 \\
& Stdev & 32.52 & 1327 \\
& & & 32.52 \\
\hline
\end{tabular}

For this reason, results from Tests 1-1 and 2-2 were discarded, leaving seven data sets as shown in Table 5. The average tensile strength of plain VHSC was 903 psi (6.23 MPa), for VHSC reinforced with $1 / 2$ inch $(13 \mathrm{~mm})$ micro-fiber was 1110 psi $(7.65 \mathrm{MPa})$ or $23 \%$ increase over the plain VHSC. For VHSC with 1 inch $(25 \mathrm{~mm})$ polypropylene fibers the average tensile strength was $1327 \mathrm{psi}(9.15 \mathrm{MPa})$ which is $47 \%$ increase. The rigid test fixture connections resulted in a uniform crack opening at the notched location as shown in Fig. 12. It should be noted that the direct tension experiments were done in addition to the flexural test to determine the ultimate tensile strength and to validate the modulus calculated from the flexural test. The average modulus of rupture calculated from the flexural tests was $2320 \mathrm{psi}$, 2565 psi and 2715 psi for plain VHSC, VHSC reinforced with $1 / 2$ inch $(13 \mathrm{~mm})$ micro-fiber and VHSC with 1 inch (25 $\mathrm{mm}$ ) polypropylene fibers, respectively.

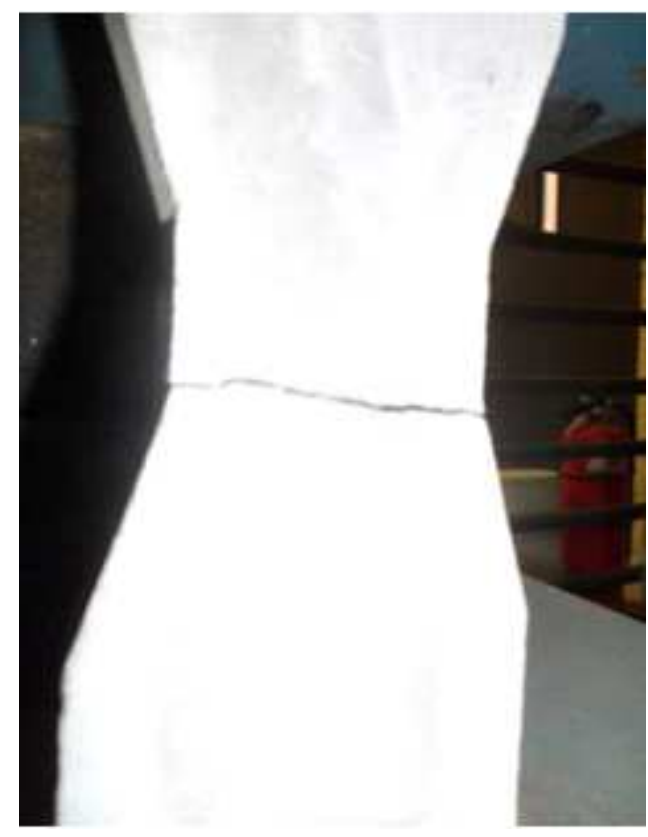

Fig. 12. Tension Test 2-1, Cracked Specimen at Test Completion

Table 6. Modulus of Elasticity and Poisson's Ratio of VHSC

\begin{tabular}{|c|c|c|c|}
\hline Type & Specimen & $\begin{array}{l}\text { Modulus of } \\
\text { Elasticity (E) } \\
\text { (psi) }\end{array}$ & $\begin{array}{l}\text { Poisson's } \\
\text { Ratio (v) }\end{array}$ \\
\hline \multirow[t]{5}{*}{ Plain VHSC } & $1--1$ & $8.57 \mathrm{E}+06$ & 0.217 \\
\hline & $1--2$ & $8.73 E+06$ & 0.225 \\
\hline & Mean & $8.65 E+06$ & 0.221 \\
\hline & Standard & & \\
\hline & Deviation & $1.13 \mathrm{E}+05$ & 0.005 \\
\hline VHSC with & $2--1$ & $5.22 \mathrm{E}+06$ & 0.215 \\
\hline \multirow[t]{4}{*}{ Micro-fiber } & $2--2$ & $7.24 \mathrm{E}+06$ & 0.211 \\
\hline & Mean & $6.23 \mathrm{E}+06$ & 0.213 \\
\hline & Standard & & \\
\hline & Deviation & $1.43 \mathrm{E}+06$ & 0.003 \\
\hline VHSC with & $3--1$ & $6.23 \mathrm{E}+06$ & 0.196 \\
\hline Polypropylene & $3--2$ & $5.81 \mathrm{E}+06$ & 0.199 \\
\hline \multirow[t]{4}{*}{ fibers } & $3--3$ & $7.18 \mathrm{E}+06$ & 0.204 \\
\hline & Mean & $6.40 \mathrm{E}+06$ & 0.200 \\
\hline & Standard & & \\
\hline & Deviation & $7.00 \mathrm{E}+05$ & 0.004 \\
\hline
\end{tabular}

Modulus of Elasticity and Poisson's ratio of VHSC: 4 inch by 8 inch cylinders of VHSC concrete specimens (plain, VHSC with micro-fiber and VHSC with polypropylene fibers) were tested in compression to determine modulus of Elasticity and Poisson's ratio according to ASTM C 469. The specimens were loaded at a rate of $12,000 \mathrm{lbs} \mathrm{min}^{-1}$ to predetermined load of $0.40 \mathrm{f}_{\mathrm{c}}$. The specimens were then completely unloaded at approximately the same rate and the gages zeroed. 
Taher M. Abu-Lebdeh et al. / American Journal of Engineering and Applied Sciences 5 (2) (2012) 184-197

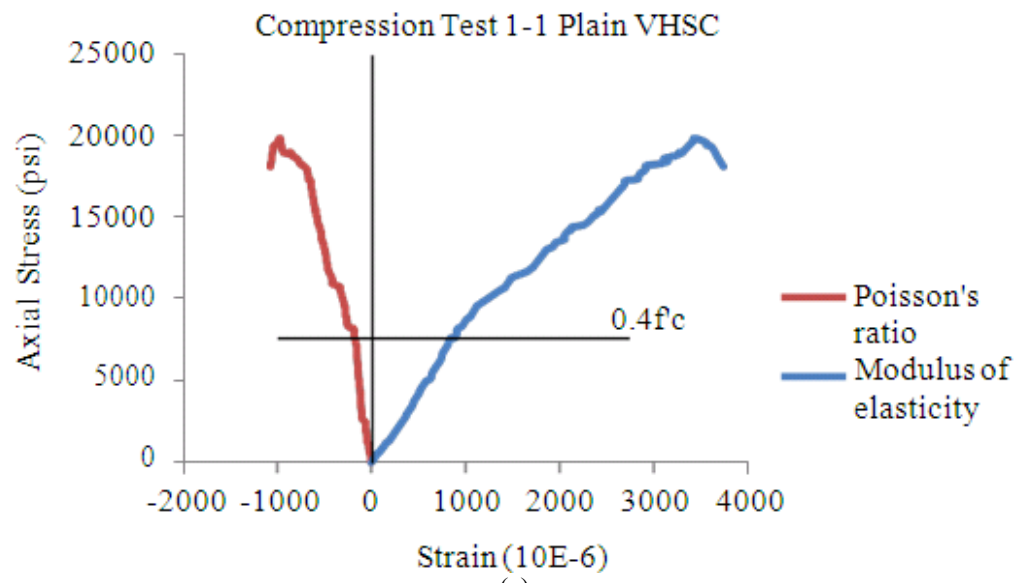

(a)

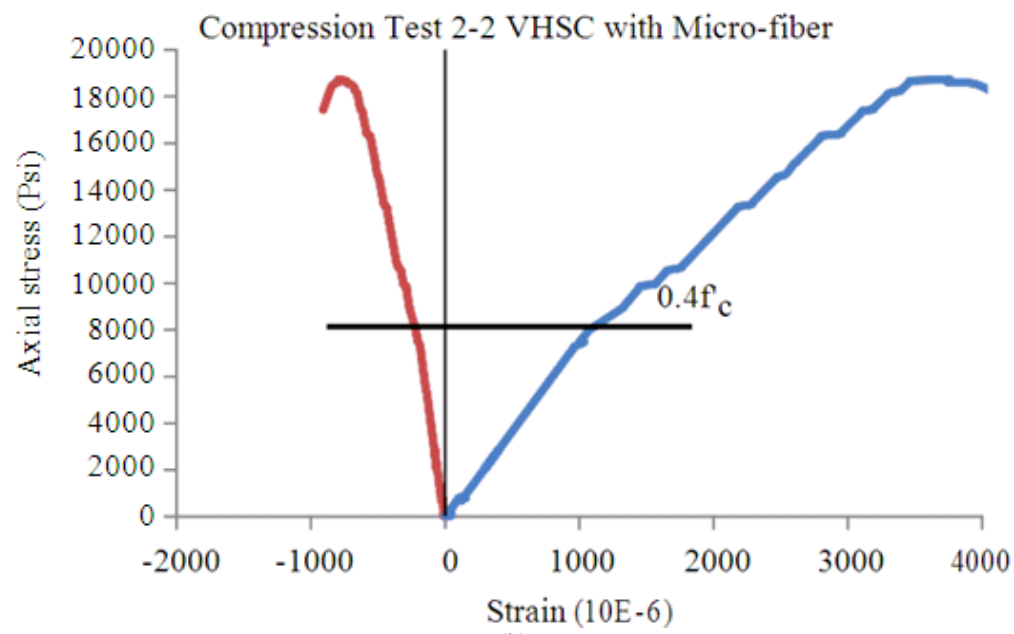

(b)

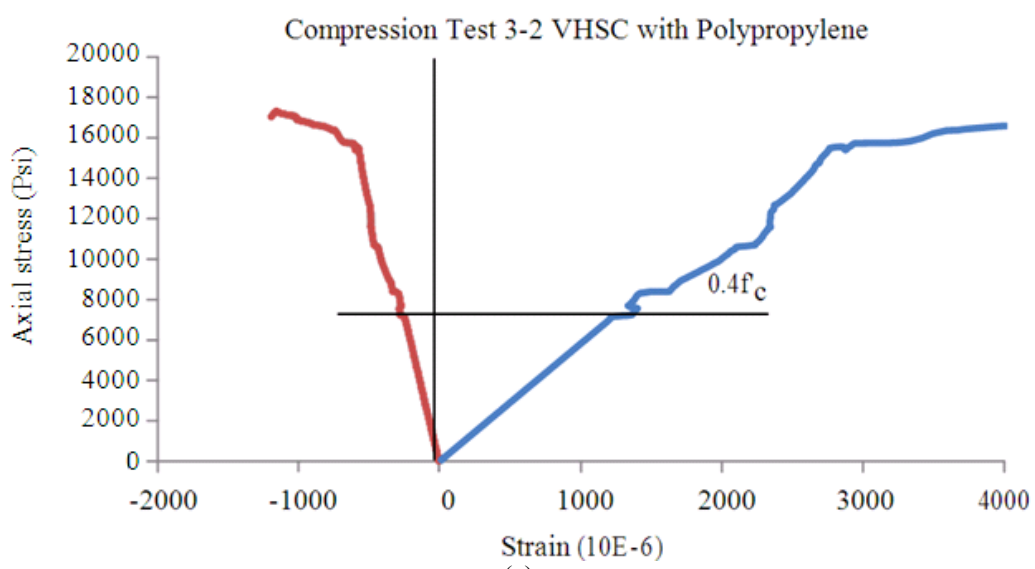

(c)

Fig. 13. Modulus of Elasticity and Poisson's ratio of VHSC specimens (a) Plain VHSC (b) VHSC reinforced with Micro-fiber (c) HSC reinforced with Polypropylene Fibers 
This process was repeated three times for each specimen, following the ASTM procedure. Data from the linear elastic portions of the compressive stress-strain curve up to $40 \%$ of the ultimate strength of the three loadings were averaged and reported in Table 6 and shown in Fig. 13 for selected specimens. The Poisson's ratio calculated by dividing the transverse strain $\left(\varepsilon_{\text {tyans }}\right)$ by the longitudinal strain $\left(\varepsilon_{\text {longitudinal }}\right)$ was found to be 0.221 for plain VHSC, 0.213 for VHSC with micro-fiber and 0.200 for VHSC with polypropylene.

\section{DISCUSSION}

\subsection{Compressive Strength}

In accordance with the requirements of ASTM (2009), all specimens were soaked in water for a period of 24 hours to 72 hours prior to testing. Specimens were weighed before and after soaking and the average absorption (by weight) of VHSC specimens was calculated to be 0.32 . This value is significantly less than that of the conventional concrete with absorption of $3 \%$ or more. The low absorption of VHSC specimens indicates that the minimization of voids (macro-defects) significantly improves the compressive strength of the material. However, the addition of fibers decreases the compressive strength as shown in Table 2. Also, it was found that the addition of $1 / 2$ " micro-fiber and 1 " Polypropylene fibers contributes to 3.6 and $9.5 \%$ reduction in Poisson's ratio, respectively. The modulus of elasticity decreases by $27 \%$ as shown in Table 6 .

\subsection{Flexural Properties}

A review of the flexural strength or first-crack strength $\left(\sigma_{y}\right)$ expression in Equation 2 shows that the expression is simply a form of the elastic flexure formula (Beer et al., 2011). For a differential specimen length, this formula assumes: (1) the length is subjected to pure bending, thus constant curvature; (2) Plane surfaces through the cross-section remain plane during bending; (3) linear stress and strain through the thickness; and (4) The material is homogeneous. The first assumption was accepted because of the fact that the first crack was calculated at the panel third-point of pure bending. Furthermore, based on the basic theories of structural mechanics, the second and third assumptions were also accepted. The fourth assumption may be satisfied by considering the macroscopic scale of the cementitous matrix and fibers which could homogenize the constituents into a uniform material of quasihomogeneous properties, thus Hooke's law of stress- strain proportionality applies. With the approval of the fourth assumption, the material's initial elastic modulus was calculated from the modulus of elasticity in Equation 3, according to ASTM (2009) which states that the flexural elastic modulus is the initial linear response of the specimen. The first crack strength computed from Equation 2 and the initial flexural modulus computed from Equation 3were reported for each test specimen in Table 3. Further, the load-displacement curves in Fig. 811 show initial linear response up to the point of firstcrack formation (flexural yield in the load-displacement curves). The reason for this behavior is that the material strained without damage. Beyond the flexural yield point, the maximum strain exceeded the strain capacity of the cementitous matrix causes the formation of local, randomly distributed, microcracks throughout the area of maximum strain in the specimen. As the load increased, in the region between the first-crack and ultimate loads, the microcracks propagate and coalesced into more extensive damage. However, the added fibers resisted the microcrack growth resulted in the observed response which may be characterized by the sharp drop in the stiffness. After full coalescence of the microcracks, a single large macrocrack formed through the specimen cross-section causing the specimens' resistance to load to quickly diminished and thus failure of the specimen. It is worth mentioning that three of the flexural specimens show fiber bridging across the macrocrack resulted in residual load capacity after the macrocrack formation.

\subsection{The Stiffness Loss Between the First-crack and Ultimate load can be Explained as Follows}

Consider the general definition of stiffness as the product of flexural modulus and moment of inertia (EI), the stiffness loss must be due to either a decrease in flexural modulus or a decrease in moment of inertia. However, the formation of macrocrack in each of the specimens suggests that the decrease in flexural modulus is the cause of stiffness loss between first-crack and ultimate loads. Although microcrack growth was the state of damage between the first-crack and ultimate loads, the damage occurred immediately after initial microcrack formation caused an initial loss of global stiffness. This reduction in global stiffness was generally constant as seen by the generally linear slope of the loaddisplacement curves. The subsequent microcrack growth did not have a significant effect until full formation of a single macrocrack occurred and corresponding total failure of the specimen. With the acceptance of the elastic flexure equation ( $4^{\text {th }}$ assumption), a reduced flexural modulus between firstcrack and ultimate load 
can be calculated using equation 4 . In Table 3 , the mean values and standard deviation have been calculated for each property of each concrete specimen. Particularly, small standard deviations were seen for the first crack load $\left(\mathrm{P}_{\mathrm{y}}\right)$, Ultimate load $\left(\mathrm{P}_{\mathrm{u}}\right)$, displacement at first crack $\left(\delta_{\mathrm{y}}\right)$, ultimate load $\left(\delta_{\mathrm{u}}\right)$ flexural strength $\left(\sigma_{\mathrm{y}}\right)$ and initial elastic modulus ( $\left.E_{\text {initial }}\right)$, post crack modulus ( $\left.E_{\text {reduced }}\right)$ with values less than approximately $15 \%$ of the mean in most cases. However, greater deviation was observed by the displacement at ultimate load $\left(\delta_{\mathrm{u}}\right)$ producing $29 \%$ for plain VHSC, the post crack modulus ( $\left.\mathrm{E}_{\text {reduced }}\right)$ produced $54 \%$ for VHSC with micro-fibers and displacement at first crack $\left(\delta_{\mathrm{y}}\right)$ produced $25 \%$ for VHSC with polypropylene fibers (expressed in terms of $\%$ of the mean). To provide direct comparison between the specimens' flexural responses, all of the load-displacement histories were plotted on a single graph in Fig. 11. From this figure, it is seen that the specimens exhibited reasonable uniformity in their initial linear response, point of first-crack formation and post-crack stiffness.

\subsection{Direct Tension}

Although there are no standardized testing procedures exist for direct tension, but to achieve accurate and meaningful direct tension data, one should consider the application of pure tensile loading without eccentricity and provide sufficient rigidity in the testing apparatus so that the crack opens uniformly across the width of the specimen. In this study, a rigid connection between the specimen and fixture was designed to ensure uniform crack opening at the cracked area as shown in Fig. 4-5. Further, the rigid plate attachment was expected to provide uniform load over the cross-section of the specimen. Recognizing these requirements, tests show a macro-crack was formed at the cracked area and grew until failure, as shown in Fig. 12. This is due to the fact that the elastic strain is significantly increases at the notch as the load approaches its maximum. A strain increase at one location and strain recovery at another resulted in strain localization, thus allow relief of strain throughout other portions of the specimen and microcracks form and coalesce at the notch . Further, test results show an average tensile strength of 903 psi for the plain VHSC with an average compressive strength of 23,500 psi. O'Neil et al. (1999) and co-researchers stated that the tensile strength of VHSC may nominally be approximately $5.5 \%$ of its compressive strength. The benefit of adding fibers to VHSC material is clear in Table 5. The tensile strength of the material increased by 23 and $47 \%$ due to the addition of $1 / 2$ " micro-fiber and 1 " fiber, respectively.
In addition to the determination of the tensile strength of VHSC material, the direct tension tests also allowed for direct observation of the fiber's bridging after crack formation in the cementitous matrix. From the literature, post-crack response of the material is governed by the bridging mechanism of the discontinuous fibers because the fibers' primary influence occurs after failure of the cementitous matrix, when microcracks propagate and coalesce into larger macrocracks. Further, in this study, the observed difference in the post-crack response was due to the nature of fibers' failure. Some specimens show fiber pullout from the cementitous matrix while others show fiber rupture because of insufficient bond strength between the fiber and the matrix.

\section{CONCLUSION}

The main purpose of this investigation was to conduct laboratory experiments to characterize the flexural and tensile behavior of fiber reinforced Very High Strength Concrete (VHSC) thin panels. The panels were made with a unique VHSC mix and $1.5 \%$ by volume of 1" long discontinuous Alkali-resistant polypropylene fibers and 1/2" Polyvinyl Alcohol (PVA) micro-fibers. Experiments included third-point flexural tests and direct tension test. Compression tests conducted on 2 inch cubes and on 4 inch by 8 inch cylinders were used to establish compressive strength and modulus of elasticity respectively. Compressive strengths of 23,500 psi $(162 \mathrm{MPa})$ or greater were obtained. The following observations and conclusions can be drawn.

The flexural third-point loading tests showed that specimens exhibited three distinct phases of flexural response. The initial response in the first stage can be characterized by linear response up to first crack load. The mean modulus and cracking strength (modulus of rupture) calculated for this stage were $5.91 \mathrm{E}+06 \mathrm{psi}$ and 1,810 psi for plain VHSC, 6.20E +06 psi and 1,900 psi for VHSC with micro-fiber and 4.79E+06 psi and 1,920 psi for VHSC with polypropylene fibers. The second stage of the flexural load-displacement curves showed a sharp transition into a softened response that may be characterized by reasonably linear relationship, which progressed to the ultimate load. The mean load capacity increase between the first-crack and the ultimate failure was approximately $28 \%$ of the first crack load for plain VHSC, $35 \%$ for VHSC with micro-fiber and $42 \%$ for VHSC with polypropylene fibers. The mean reduced modulus was calculated to be $1.36 \mathrm{E}+06$ psi for plain VHSC, $1.05 \mathrm{E}+06$ psi for VHSC with micro-fiber and 
$0.69 \mathrm{E}+06$ psi for VHSC with polypropylene fibers. In the third stage, once the ultimate load was reached, the panels failed abruptly with the development of a single macrocrack and a swift loss of load resistance. Some panels showed small residual load-carrying capacity.

Defining toughness or fracture energy as the area under the load-displacement curves, the inclusion of fibers increased the panel toughness between $90 \%$ and $190 \%$. An increase in fiber length also increased the fracture energy from $4.70 \mathrm{lbf}-\mathrm{in} / \mathrm{in}^{2}$ for panels reinforced with $1 / 2$ inch micro-fibers to $7.11 \mathrm{lbf}-\mathrm{in} / \mathrm{in}^{2}$ for VHSC specimens with 1 inch polypropylene.

It was observed in the direct tension experiments that when the cementitous matrix ruptured, the strength dropped rapidly until the fibers were engaged to restrain crack growth and the response transitioned from brittle to more ductile. Further, fiber rupture rather than fiber pullout was observed in most cases.

The inclusion of the discontinuous reinforcing fibers improved post-crack ductility. Observed in the flexural experiments, the fiber's impact on bending response was an increase of maximum displacement from a mean value of 0.011 inch at first-crack formation to a mean value of 0.0241 inch at ultimate failure of plain VHSC; 0.0109 inch to 0.0355 inch for VHSC reinforced with micro-fiber; and from 0.0145 inch to 0.056 inch for VHSC reinforced with polypropylene fibers. This increase in failure displacement was a result of including fibers in the matrix.

\section{REFERENCES}

Abu-Lebdeh, T., S. Hamoush, W. Heard and B. Zornig, 2010. Effect of matrix strength on pullout behavior of steel fiber reinforced very-high strength concrete composites. Constr. Build. Mater. J., 25: 39-46. DOI: 10.1016/j.conbuildmat.2010.06.059

ASTM, 2002. ASTM C469 / C469M-10 standard test method for static modulus of elasticity and Poisson's ratio of concrete in compression. ASTM International. DOI: 10.1520/C0469 C0469M-10

ASTM, 2009. ASTM C947-03(2009) Standard test method for flexural properties of thin-section glassfiber-reinforced concrete (using simple beam with third-point loading). ASTM International. DOI: 10.1520/C0947-03R09

Banthia, N. and R. Gupta, 2004. Hybrid Fiber Reinforced Concrete (HyFRC): Fiber synergy in high strength matrices. Mater. Stru., 37: 707-716. DOI: $10.1007 / \mathrm{BF} 02480516$
Beer, F., J. Johnston, E. Russell, J. DeWolf and D. Mazurek, 2011. Mechanics of Materials. 6th Edn., McGraw-Hill Companies, New York, ISBN: 0073380288, pp: 832.

Chandramouli, K., P.S. Rao, N. Pannirselvam, T.S. Sekhar and P. Sravana, 2010. Chloride penetration resistance studies on concretes modified with alkali resistant glass fibers. Am. J. Applied Sci., 7: 371-375. DOI: 10.3844/ajassp.2010.371.375

Kanda, T. and V.C. Li, 1999. Effect of fiber strength and fiber-matrix interface on crack bridging in cement composites. J. Eng. Mech., 125: 290-299. DOI: 10.1061/(ASCE)0733-9399(1999)125:3(290)

Li, V.C. and S. Wang, 2006. Microstructure variability and macroscopic composite properties of high performance fiber reinforced cementitious composites. Probabilistic Eng. Mech., 21: 201-206.

Nelson, P., V. Li and T. Kamada, 2002. Fracture toughness of microfiber reinforced cement composites. J. Mater. Civil Eng., 14: 384-391. DOI: 10.1061/(ASCE)0899-1561(2002)14:5(384)

O'Neil, E.F., B.D. Neeley and J.D. Cargile, 1999. Tensile properties of very-high-strength concrete for penetration-resistant structures. Shock Vibrat., 6: 237-245.

O'Neil, E.F., T.K. Cummins, B.P. Durst, P.G. Kinnebrew and R.N. Boone et al., 2006. Development of very high-strength and highperformance concrete materials for improvement of barriers against blast and projectile penetration. Proceeding of the 24th, US Army Science Conference, Transformational Science and Technology for the Current and Future, Nov. 29Dec. 2, World Scientific Publishing Co., Orlando, Florida.

Ramli, M., 2010. Influences of short discrete fibers in high strength concrete with very coarse sand. Am. J. Applied Sci., 7: 1572-1578. DOI: 10.3844/ajassp.2010.1572.1578

Ravichandran, A., K. Suguna and P. N. Ragunath, 2009. strength modeling of high-strength concrete with hybrid fibre reinforcement. Am. J. Applied Sci., 6: 219-223. DOI: 10.3844/ajassp.2009.219.223

Rossana, B., 2012. The effect of water on the strength of building stones. Am. J. Eng. Sci., 8: 158-161. DOI: 10.3844/ajessp.2012.158.161

Roth, M.J., 2008. Flexural and Tensile Properties of Thin, Very High-strength, Fiber-Reinforced Concrete Panels. 1st Edn., Mississippi State University, ISBN-10: 0549413472, pp: 191. 